\title{
The possible role of visceral fat in early pregnancy as a predictor of gestational diabetes mellitus by regulating adipose- derived exosomes miRNA-148 family: protocol for a nested case-control study in a cohort study
}

Zhenhong Zhang ${ }^{1 \dagger}$, Qian Xü ${ }^{2+}$, Yanping Chen ${ }^{2}$, Lun Sui ${ }^{2}$, Lu Jiang ${ }^{2}$, Qianqian Shen ${ }^{1}$, Minyu Li ${ }^{1}$, Guoju $\mathrm{Li}^{2^{*}}$ and Qiuzhen Wang ${ }^{1 *}$ (D)

\begin{abstract}
Background: Gestational diabetes mellitus (GDM) has become alarming public health concern. It is associated with adverse pregnancy outcomes and increased risk of postpartum type 2 diabetes. Pre-pregnant body mass index (BMI), waist circumference and other anthropometric parameters have been proposed to predict GDM. However, visceral fat thickness can better reflect the distribution of body fat, and may more accurately predict the risk of GDM. Visceral fat thickness may lead to insulin resistance by regulating the adipose-derived exosomes miRNA-148 family, which affect the development of GDM. Evidence from prospective cohort studies on visceral fat thickness as a predictor of GDM and the possible mechanisms is still insufficient.

Methods: In this prospective cohort study, we will recruit 3000 women at first antenatal visit between 4 and 12 weeks of gestation. Baseline socio-demographic factors and visceral fat thickness will be assessed by questionnaire form and the ultrasonic measurement, respectively. At 20 weeks of gestation, $10 \mathrm{ml}$ blood samples will be drawn and we will extract adipose-derived exosomes miRNA on the basis of nested case-control study. GDM will be screened at 24-28 weeks' gestation and the expression of miRNA-148 family between pregnant women with GDM and without GDM will be analyzed. Intermediary analysis will be used to investigate whether visceral fat thickness can predict GDM by regulating adipose-derived exosomes miRNA-148 family.
\end{abstract}

\footnotetext{
*Correspondence: liquoju0532@126.com; qdwangqiuzhen@126.com

'Zhenhong Zhang and Qian Xu contributed equally to this work.

'Public Health School, Medical College of Qingdao University, Qingdao,

China

${ }^{2}$ Qingdao Women and Children's Hospital, Qingdao University, No. 6 Tongfu

Road, Qingdao 266000, Shandong Province, China
}

(c) The Author(s). 2021, corrected publication 2021. Open Access This article is licensed under a Creative Commons Attribution 4.0 International License, which permits use, sharing, adaptation, distribution and reproduction in any medium or format, as long as you give appropriate credit to the original author(s) and the source, provide a link to the Creative Commons licence, and indicate if changes were made. The images or other third party material in this article are included in the article's Creative Commons licence, unless indicated otherwise in a credit line to the material. If material is not included in the article's Creative Commons licence and your intended use is not permitted by statutory regulation or exceeds the permitted use, you will need to obtain permission directly from the copyright holder. To view a copy of this licence, visit http://creativecommons.org/ licenses/by/4.0/. The Creative Commons Public Domain Dedication waiver (http://creativecommons.org/publicdomain/zero/1. 0/) applies to the data made available in this article, unless otherwise stated in a credit line to the data. 
(Continued from previous page)

Discussion: We hypothesized that visceral fat thickness may predict GDM by regulating the miRNA-148 family of adipose-derived exosomes. The findings of the study will assist in further clarifying the pathophysiological mechanism of GDM, it will also provide technical support for effective screening of high-risk pregnant women with GDM.

Keywords: Visceral fat, Adipose-derived exosomes, miRAN-148 family, Gestational diabetes mellitus

\section{Background}

Gestational diabetes mellitus (GDM) is a common complication of pregnancy, affecting $7-25 \%$ of pregnancies worldwide $[1,2]$, forming a severe public health concern. GDM contributes to the occurrence of preeclampsia [3], gestational hypertension [4], macrosomia [5] and preterm birth [6]. It is also associated with long-term adverse outcomes in postpartum women and offspring, including increased risk of developing obesity [7], cardiovascular disease [8] and type 2 diabetes [9]. Previous study reported that the incidence of GDM in Asia was as high as $20.9 \%$ [10]. A systematic review [11] suggested that the incidence of GDM in Chinese mainland was $14.8 \%$, which indicated that China might have the largest number of GDM patients in the world. The city of Qingdao, the cite of our field work, had an incidence of GDM as $17.4 \%$ [12], which was higher than that reported as the average level in the mainland of China. In recent years, there is an increasing trend in the prevalence of GDM globally, including in China [13-15]. In view of the adverse consequences and high prevalence of GDM, identifying the major risk factors for GDM in an early stage of the pregnant is essential.

Risk factors such as pre-pregnancy overweight and obesity [16], advanced maternal age [17], family history of diabetes [18] have been proposed to be related to the incidence of GDM, previously. However, different from those constant risk factors, overweight/obesity is a potentially modifiable factor of GDM. Accordingly, body mass index (BMI), waist circumference and other related anthroprometric parameters have been proposed to predict GDM. However, their predictive power for GDM was controversial. Visceral fat, better reflecting of the distribution of body fat [19], has been reported to play an important role in the prevalence of GDM $[20,21]$. A cohort study [22] showed that visceral fat may be a powerful predictor of GDM. Additionally, another study concluded that the accuracy of visceral fat thickness in early pregnancy to predict GDM may be better than that of BMI [20]. However, the pathogenesis of GDM due to visceral fat remains largely unknown. In recent years, studies have shown that adipose-derived exosomes play a significant role in the occurrence and development of GDM. The research results published on journal of Cell [23] in 2017 showed that adipose tissue in obese mice secreted miRNA-containing exosomes, which induced glucose intolerance and insulin resistance when administered to lean mice. In the process, adipose-derived exosomes miRNA played an important role. Another research indicated that visceral adipose-derived exosomes participated in receptor-insulin signal transduction through down-regulation of miRNA-148-a and miRNA-148-b expression [24-26]. Therefore, the abnormal expression of miRNA in adipose-derived exosomes caused by visceral fat accumulation may be an important mechanism in the pathogenesis of GDM.

We hypothesized that visceral fat thickness may predict GDM by regulating the adipose-derived exosomes miRNA-148 family, and verify this hypothesis in a cohort \& nested case-control study.

\section{Methods/design \\ Study design}

This is a prospective cohort study, and it will follow the requirements of strengthening observational study reports in the guidelines for epidemiological reporting of cohort studies. Meanwhile, in order to explore the mechanism of visceral fat thickness influencing GDM by regulating adipose-derived exosomes miRNA, we organized a 1:1 nested case-control study according to age \pm 2 years old from the prospective cohort of pregnant women.

\section{Study objectives}

1. To explore the influence of BMI and visceral fat thickness in early pregnancy on GDM, and select the appropriate adiposity indicator.

2. To evaluate the expression of adipose-derived exosomes miRNA-148 family in pregnant women with GDM and without GDM, and study how visceral fat thickness regulates the miRNA-148 family of adipose-derived exosomes to cause GDM.

\section{Recruitment of participants}

Study recruitment started on 1 April 2019 at Qingdao Women and Children's Hospital and it is expected to last until April 2021. It will have to meet the following criteria: 


\section{Inclusion criteria}

(1) Singleton pregnancy; (2) First antenatal visit is 4-12 weeks of gestation; (3) Age $\geq 20$ years; (4) The target pregnant women are permanent residents in Qingdao.

\section{Exclusion criteria}

(1) Without definite date of last menstruation; (2) With kidney and other endocrine diseases; (3) With cardiovascular and cerebrovascular diseases and important organ dysfunction; (4) Refusal of follow-up.

\section{Plan of follow-up}

At 20 weeks of gestation, $10 \mathrm{ml}$ blood samples will be drawn and we will extract adipose-derived exosomes miRNA. GDM will be screened at 24-28 weeks' gestation and we organized a 1:1 nested case-control study according to age \pm 2 years old from pregnant women, the expression of miRNA-148 family between pregnant women with GDM and without GDM will be analyzed. Technical roadmap of this research project can be found in Fig. 1 and a schematic schedule of enrolment and assessments can be found in Fig. 2.

\section{Outcome measures \\ Primary outcomes}

The central outcome variable is GDM. During 24-28 weeks of gestation, $75 \mathrm{~g}$ oral glucose tolerance test (OGTT) will be carried out to detect the blood glucose level. According to the International Association of Diabetes and Pregnancy Study Groups (IADPSG) standard [27], GDM will be diagnosed if subjects meet at least one of the following criteria: (1) fasting venous blood glucose of $\geq 5.1 \mathrm{mmol} / \mathrm{L}$; (2) 1 -h venous blood glucose of $\geq 10.0 \mathrm{mmol} / \mathrm{L}$; (3) 2 -h venous blood glucose of $\geq 8.5$ $\mathrm{mmol} / \mathrm{L}$.

\section{Secondary outcomes}

The secondary outcomes of this study include: weight gain and results of blood pressure monitoring at 20 and 24-28 weeks of gestation, respectively.

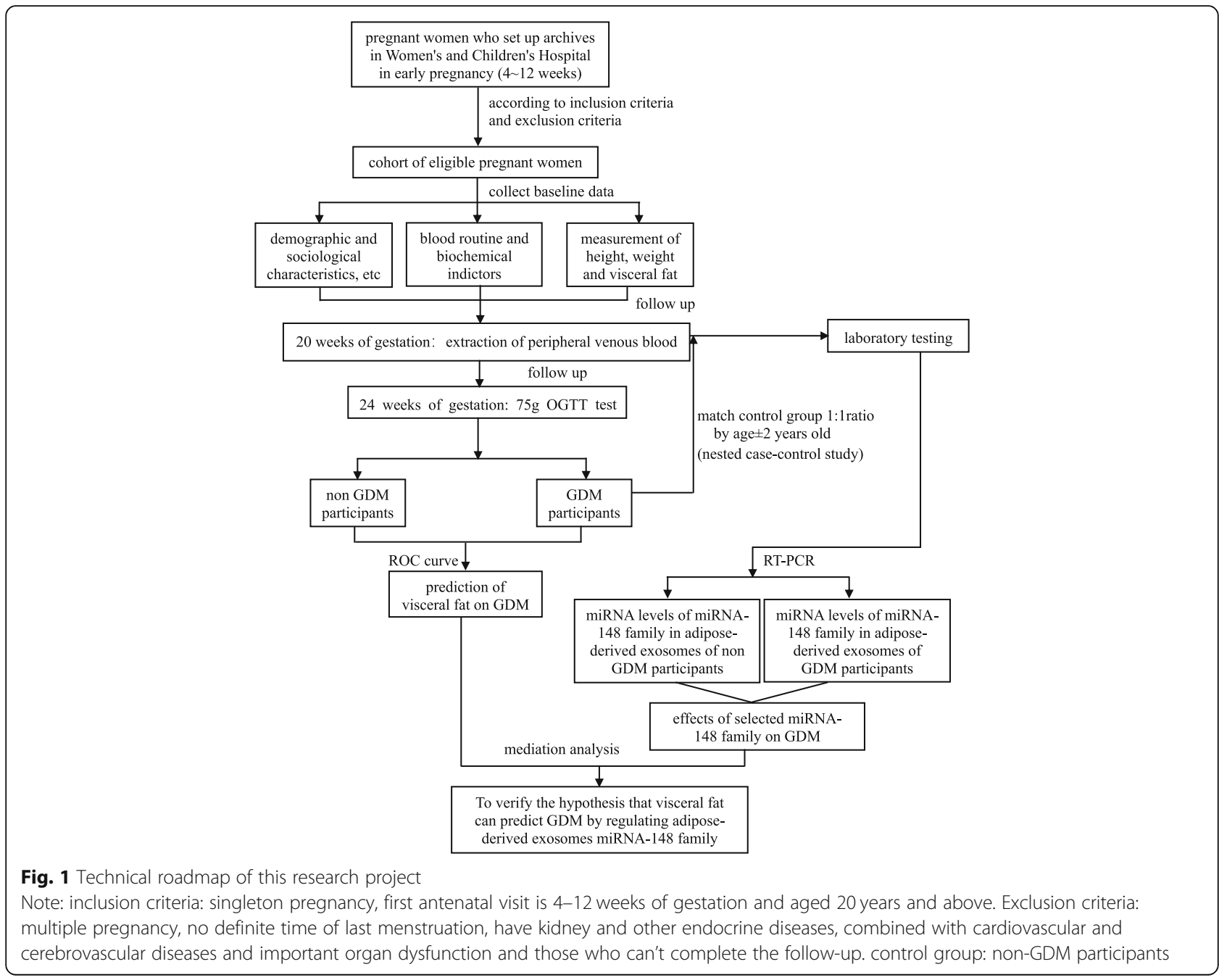




\begin{tabular}{|c|c|c|c|}
\hline \multirow{2}{*}{ Timepoint } & \multicolumn{3}{|c|}{ Study period } \\
\cline { 2 - 4 } & Enrolment & \multicolumn{2}{|c|}{ Post-allocation } \\
\hline Baseline work: & 0 & $t_{1}$ & $t_{2}$ \\
\hline Eligibility screen & $\times$ & & \\
\hline Informed consent & $\times$ & & \\
\hline Questionnaire investigation & $\times$ & & \\
\hline Biochemical examination & $\times$ & & \\
\hline Physical examination & $\times$ & & \\
\hline Follow up work: & & & \\
\hline Extraction of venous blood & & & \\
\hline $\begin{array}{c}\text { Gestational diabetes screening } \\
\text { Assessments: }\end{array}$ & & & \\
\hline $\begin{array}{c}\text { Match control group by } \\
\text { 1:1ratio, and levels of adipose- } \\
\text { derived exosomes miRNA 148 } \\
\text { family were detected and } \\
\text { compared between the GDM } \\
\text { group and non-GDM group }\end{array}$ & & & \\
\hline
\end{tabular}

Fig. 2 Schedule of enrolment, follow-up and assessments

\section{Data collection}

\section{Research questionnaire form}

Sociodemographic information include age, education level, personal monthly income and working status during pregnancy will be collected by questionnaire. Behavior and lifestyle include smoking, drinking and physical activity. Parity, personal and family disease history will also be collected. The questionnaire is shown in Additional file 1.

\section{Physical measurement}

Standardized measurements of height, weight, waist circumference will be performed, and blood pressure will also be measured by using an internationally certified Omron electronic sphygmomanometer (hem-7220). In addition, visceral fat thickness will be measured by ultrasonographic, defined as the distance between the internal face of reto-abdominal muscle and the anterior wall of the aorta [28]. The standardized measurement method greatly reduces the potential data deviation and ensures the real reliability of the data.

\section{Laboratory measurement}

In the Clinical Laboratory of Qingdao Women's and Children's Hospital, routine blood, blood biochemical indices, and adipose-derived exosomes will be carried out. Based on the experimental method of Real-Time Fluorescence Quantitative PCR (RT-PCR), the miRNA-148 family of adipose-derived exosomes will be sequenced between pregnant woman with GDM and without GDM.

\section{Sample size calculation}

In this study, obesity was selected as the main exposure indictor to calculate the sample size, and sample size has been calculated to reach a confidence level of $95 \%$ with a power of $80 \%$ and $\alpha$ significance level of 0.05 . According to the following formula:

$$
\mathrm{N}=\left(\mathrm{z}_{\alpha} \sqrt{2 \overline{\mathrm{pq}}}+\mathrm{z}_{\beta} \sqrt{\mathrm{p}_{0} \mathrm{q}_{0}+\mathrm{p}_{1} \mathrm{q}_{1}}\right)^{2} /\left(\mathrm{p}_{1}-\mathrm{p}_{0}\right)^{2}
$$

In the light of the incidence of GDM in pregnant women with obesity before pregnancy was p1 $=0.1378$, $\mathrm{q} 1=0.8622$ and the control group was $\mathrm{p} 0=0.0564, \mathrm{q} 0=$ $0.9436, \bar{p}=0.0971, \bar{q}=0.9029$. If we assume a dropout rate of $10 \%$, taking into account the unqualified samples and expanding sample proportion of cluster sampling to 1.7 times, the sample size of each group was 600. In order to fully analyze the risk factors of GDM, lay the foundation for the follow-up cohort, and finally determine each group of 1500 people.

Based on the above information, a nested case-control study was designed to analyze the miRNA-148 family expression between pregnant women with GDM and without GDM. Briefly, we will select all GDM subjects among members of the cohort and match them with 
control subjects who reach the age \pm 2 years at the time in a $1: 1$ ratio.

\section{Ethics and dissemination}

The study was approved by the Ethics Committee of Qingdao Women's and Children's Hospital (Number: 019-2019-FEKY). Each adverse event will be reported in writing to the Ethics Committee and each revision of the study protocol will also be reported. Investigators will strictly abide by the stated commandments of Helsinki and the ethical issues of human biomedical research when conducting this study. The patient has given informed consent to participate in the study, and patient information will remain confidential throughout the study process.

\section{Statistical analysis}

Statistical analyses will be performed by using SAS 9.4 and the level of significance will be set at $p<0.05$. First, the continuous variables will be tested for normality and homogeneity of variance, If the data conform the normal distribution, participant characteristics will be described mean \pm standard deviation, and the comparison between the two groups will be used independent sample t-test; If the data does not conform the normal distribution, participant characteristics will be described interquartile ranges, and nonparametric test will be used to compare the two groups. For qualitative data, participant characteristics will be percentage, and chi square test will be used for comparison between groups. Covariate adjusted logistic regression will be used to analyze the possible influencing factors of GDM. Receiver Operator Characteristic (ROC) curve will be used to identify the best cut-off value of visceral fat thickness and BMI to predict GDM among all patients. The area under the ROC curve (AUC) of visceral fat thickness and BMI will be compared by z-test and we will select the appropriate adiposity indicator. Multiple imputation will be used for missing data.

Mediation analysis will be used to explore the relationship between visceral fat thickness and GDM by regulating adipose-derived exosomes miRNA-148 family. It divides the effect of an exposure on the outcome to two parts, one is the direct effect and the other is the indirect effect. The effect of the visceral fat (exposure factor) on the GDM that is not through the adipose-derived exosomes miRNA-148 family is referred to as a direct effect. The effect of the visceral fat (exposure factor) on the GDM that operates through adipose-derived exosomes miRNA-148 family is referred to as an indirect effect. And the adiposederived exosomes miRNA-148 family is referred to as "mediator". The sketch map was shown in Fig. 3.

\section{Study status}

Recruitment has started April 2019 and it is estimated it will take 3 years for full recruitment.

\section{Discussion}

Our study is a population-based study aimed to assess accuracy of visceral fat thickness in predicting GDM and the visceral fat how regulates the miRNA-148 family of adipose-derived exosomes to cause GDM. Currently, more and more scholars discuss the predictive efficiency of anthropometric parameters for GDM [29-31]. However, there were few studies on the prediction of visceral fat thickness to GDM, moreover, the pathogenesis of visceral fat leading to GDM was unclear. At present, extensive efforts are being focused on the adipose-derived exosomes in relation to GDM. Previous study found that adipose-derived exosomes were the main source of circulating miRNA [32], these circulating miRNAs played an important role in regulating mRNA expression and translation. Adipose-derived exosomes miRNA were also associated with development of insulin resistance. The analysis of adipose-derived exosomes miRNA content pre- and post-gastric bypass showed upregulation of miR103-3p which was known to target the insulin receptor signaling pathway and was previously found to be downregulated in diabetes [33-35]. These studies demonstrated that adipose-derived exosomes can mediate gene regulation and functioning in distant cells. Therefore, in obese pregnancies, adipose-derived exosomes may communicate with the placenta and induce changes in its function which may contribute to the development of GDM. Thus, it is possible that adipose-derived exosomes were factors in the pathogenesis of GDM. However, there were few studies about visceral fat regulating

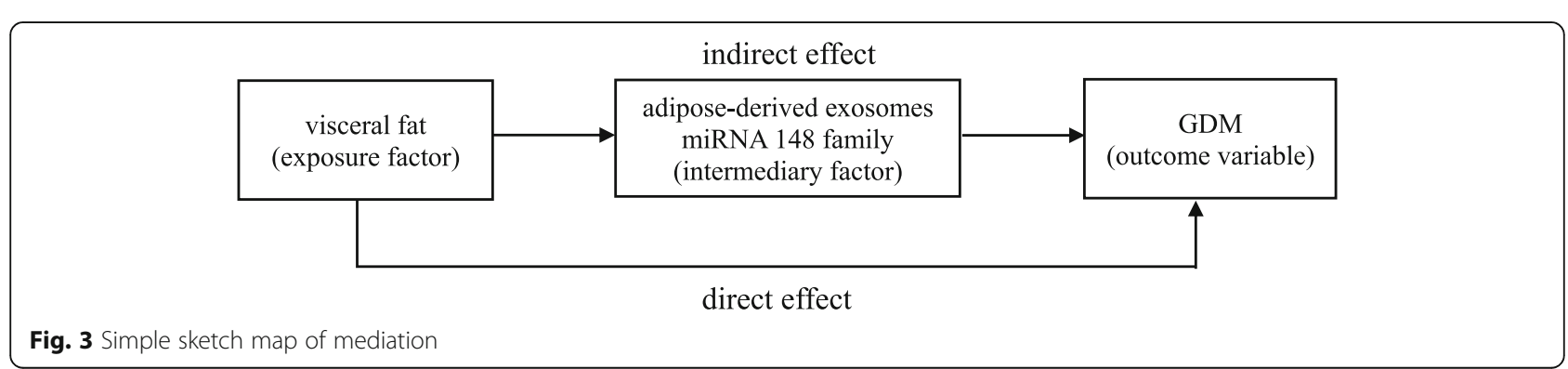


the miRNA-148 family of adipose-derived exosomes to cause GDM, so we designed this study.

Our research has some advantages. Firstly, our case control study will be nested within a prospective cohort and the measurement of visceral fat thickness and adipose-derived exosomes miRNA-148 family will prior to the diagnosis of GDM, which allow us to estimate the causal relationship of visceral fat thickness on the development of GDM, although there are more and more studies on the effect of adipose-derived exosomes on diseases, our study nested case-control study on the basis of prospective cohort study, which is more scientific and reliable. Secondly, nested case-control study will save time, effort, and money. Thirdly, the GDM cases will be confirmed by medical records following a clear definition based on IADPSG guidelines rather than selfreported and it will guarantee reliability of results. However, on the basis of cohort study, a limitation of this study is loss of follow-up, but we will keep in touch with pregnant women at any time through wechat, which will greatly reduce our loss rate.

In conclusion, to a certain extent, the study is helpful to verify the effect of visceral fat on the development of GDM, and it is helpful to further clarify the pathophysiological mechanism of gestational diabetes. It also provides technical support for effective screening of high-risk pregnant women with GDM.

\section{Abbreviations}

GDM: Gestational diabetes mellitus; BMI: Body mass index; OGTT: Oral glucose tolerance test; IADPSG: International Association of Diabetes and Pregnancy Study Groups; RT-PCR: Real-Time Fluorescence Quantitative PCR; ROC: Receiver Operator Characteristic

\section{Supplementary Information}

The online version contains supplementary material available at https://doi. org/10.1186/s12884-021-03737-1.

Additional file 1. Questionnaire

\section{Acknowledgements}

The authors would like to thank the participants of the study for their willingness to participate.

\section{Authors' contributions}

QW and GL conceived and designed the study. ZZ and QX drafted the manuscript. YC, LS, LJ, QS and ML participated in the recruitment of personnel. All authors read and approved the final manuscript.

\section{Funding}

This work was supported by National Natural Science Foundation of China (NSFC) [Grant No.81903335]. The funders provided financial support for this study, which was used for the purchase of various experimental equipment and biochemical tests.

\section{Availability of data and materials}

The anonymised datasets used and/or analysed during the current study will be available from the corresponding author on reasonable request.

\section{Declarations}

Ethics approval and consent to participate

Ethical approval for this study has been obtained from the Ethics Committee of Qingdao Women's and Children's Hospital (Number: 019-2019-FEKY). All participants sign a consent form prior to participating in the study.

\section{Consent for publication}

Not applicable.

\section{Competing interests}

The authors declare that they have no competing interests.

Received: 25 February 2021 Accepted: 18 March 2021

Published online: 30 March 2021

\section{References}

1. Guariguata $L$, Linnenkamp U, Beagley J, Whiting DR, Cho NH. Global estimates of the prevalence of hyperglycaemia in pregnancy. Diabetes Res Clin Pract. 2014;103(2):176-85. https://doi.org/10.1016/j.diabres.2013.11.003.

2. Ferrara A. Increasing prevalence of gestational diabetes mellitus: a public health perspective. Diabetes Care. 2007;30(Suppl 2):S141-6. https://doi.org/1 $0.2337 /$ dc07-s206.

3. Kang L, Li HY, Ou HY, Wu P, Wang SH, Chang CJ, et al. Role of placental fibrinogen-like protein 1 in gestational diabetes. Transl Res. 2020;218:73-80. https://doi.org/10.1016/j.trsl.2020.01.001

4. Daly B, Toulis KA. Increased risk of ischemic heart disease, hypertension, and type 2 diabetes in women with previous gestational diabetes mellitus, a target group in general practice for preventive interventions: A populationbased cohort study. PloS Med. 2018;15(1):e1002488.

5. Plows JF, Stanley JL, Baker PN, Reynolds CM, Vickers MH. The Pathophysiology of Gestational Diabetes Mellitus. Int J Mol Sci. 2018;19(11): 3342.

6. Billionnet C, Mitanchez D, Weill A, Nizard J, Alla F, Hartemann A, et al. Gestational diabetes and adverse perinatal outcomes from 716,152 births in France in 2012. Diabetologia. 2017;60(4):636-44. https://doi.org/10.1007/ s00125-017-4206-6.

7. Mclntyre HD, Catalano P, Zhang C, Desoye G, Mathiesen ER, Damm P. Gestational diabetes mellitus. Nat Rev Dis Primers. 2019;5(1):47. https://doi. org/10.1038/s41572-019-0098-8.

8. Leybovitz-Haleluya N, Wainstock T, Landau D, Sheiner E. Maternal gestational diabetes mellitus and the risk of subsequent pediatric cardiovascular diseases of the offspring: a population-based cohort study with up to 18 years of follow up. Acta Diabetol. 2018;55(10):1037-42. https://doi.org/10.1007/s00592-018-1176-1.

9. Vounzoulaki E, Khunti K, Abner SC, Tan BK, Davies MJ, Gillies CL. Progression to type 2 diabetes in women with a known history of gestational diabetes: systematic review and meta-analysis. Bmj. 2020;369:m1361.

10. Lee KW, Ching SM, Ramachandran V, Yee A, Hoo FK, Chia YC, et al. Prevalence and risk factors of gestational diabetes mellitus in Asia: systematic review and meta-analysis. BMC Pregnancy Childbirth. 2018;18(1): 494. https://doi.org/10.1186/s12884-018-2131-4.

11. Gao C, Sun X. Prevalence of gestational diabetes mellitus in mainland China: A systematic review and meta-analysis. J Diabetes Investig. 2019; 10(1):154-62.

12. Li G, Wei T, Ni W, Zhang A, Zhang J, Xing Y, et al. Incidence and risk factors of gestational diabetes mellitus: a prospective cohort study in Qingdao, China. Front Endocrinol (Lausanne). 2020;11:636. https://doi.org/10.3389/ fendo.2020.00636.

13. Zhang F, Dong L, Zhang CP, Li B, Wen J, Gao W, et al. Increasing prevalence of gestational diabetes mellitus in Chinese women from 1999 to 2008. Diabet Med. 2011;28(6):652-7. https://doi.org/10.1111/j.1464-5491.2010.032 05.x.

14. Wang Y, Chen L, Xiao K, Horswell R, Besse J, Johnson J, et al. Increasing incidence of gestational diabetes mellitus in Louisiana, 1997-2009. J Women's Health (Larchmt). 2012;21(3):319-25. https://doi.org/10.1089/jwh.2 011.2838 .

15. Rajab KE, Issa AA, Hasan ZA, Rajab E, Jaradat AA. Incidence of gestational diabetes mellitus in Bahrain from 2002 to 2010. Int J Gynaecol Obstet. 2012; 117(1):74-7. https://doi.org/10.1016/j.jjgo.2011.11.013. 
16. Lewandowska M, Więckowska B, Sajdak S. Pre-Pregnancy Obesity, Excessive Gestational Weight Gain, and the Risk of Pregnancy-Induced Hypertension and Gestational Diabetes Mellitus. J Clin Med. 2020;9(6):1980.

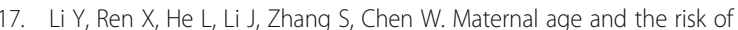
gestational diabetes mellitus: a systematic review and meta-analysis of over 120 million participants. Diabetes Res Clin Pract. 2020;162:108044. https:// doi.org/10.1016/j.diabres.2020.108044.

18. Aydın H, Çelik Ö, Yazııı D, Altunok Ç, Tarçın Ö, Deyneli O, et al. Prevalence and predictors of gestational diabetes mellitus: a nationwide multicentre prospective study. Diabet Med. 2019;36(2):221-7. https://doi.org/10.1111/ dme.13857.

19. Swainson MG, Batterham AM, Tsakirides C, Rutherford ZH, Hind K. Prediction of whole-body fat percentage and visceral adipose tissue mass from five anthropometric variables. Plos One. 2017;12(5):e0177175. https://doi.org/1 0.1371/journal.pone.0177175.

20. Gur EB, Ince O, Turan GA, Karadeniz M, Tatar S, Celik E, et al. Ultrasonographic visceral fat thickness in the first trimester can predict metabolic syndrome and gestational diabetes mellitus. Endocrine. 2014; 47(2):478-84. https://doi.org/10.1007/s12020-013-0154-1.

21. De Souza LR, Berger $H$, Retnakaran R, Vlachou PA, Maguire JL, Nathens AB, et al. Hepatic fat and abdominal adiposity in early pregnancy together predict impaired glucose homeostasis in mid-pregnancy. Nutr Diabetes. 2016;6(9):e229. https://doi.org/10.1038/nutd.2016.39.

22. Balani J, Hyer $\mathrm{S}$, Johnson A, Shehata $H$. The importance of visceral fat mass in obese pregnant women and relation with pregnancy outcomes. Obstet Med. 2014;7(1):22-5. https://doi.org/10.1177/1753495X13495192.

23. Ying W, Riopel M, Bandyopadhyay G, Dong Y, Birmingham A, Seo JB, et al. Adipose Tissue Macrophage-Derived Exosomal miRNAs Can Modulate In Vivo and In Vitro Insulin Sensitivity. Cell. 2017;171(2):372-384.e312.

24. Yang Z, Wei Z, Wu X, Yang H. Screening of exosomal miRNAs derived from subcutaneous and visceral adipose tissues: determination of targets for the treatment of obesity and associated metabolic disorders. Mol Med Rep. 2018;18(3):3314-24. https://doi.org/10.3892/mmr.2018.9312.

25. Londoño Gentile T, Lu C, Lodato PM, Tse S, Olejniczak SH, Witze ES, et al. DNMT1 is regulated by ATP-citrate lyase and maintains methylation patterns during adipocyte differentiation. Mol Cell Biol. 2013;33(19):3864-78. https:// doi.org/10.1128/MCB.01495-12.

26. Ferrante SC, Nadler EP, Pillai DK, Hubal MJ, Wang Z, Wang JM, et al. Adipocyte-derived exosomal miRNAs: a novel mechanism for obesityrelated disease. Pediatr Res. 2015;77(3):447-54. https://doi.org/10.1038/pr.2 014.202.

27. Metzger BE, Gabbe SG, Persson B, Buchanan TA, Catalano PA, Damm P, et al. International association of diabetes and pregnancy study groups recommendations on the diagnosis and classification of hyperglycemia in pregnancy. Diabetes Care. 2010;33(3):676-82. https://doi.org/10.2337/dc09-1 848.

28. Stolk RP, Meijer R, Mali WP, Grobbee DE, van der Graaf Y. Ultrasound measurements of intraabdominal fat estimate the metabolic syndrome better than do measurements of waist circumference. Am J Clin Nutr. 2003. 77(4):857-60. https://doi.org/10.1093/ajcn/77.4.857.

29. Basraon SK, Mele L, Myatt L, Roberts JM, Hauth JC, Leveno KJ, et al. Relationship of early pregnancy waist-to-hip ratio versus body mass index with gestational diabetes mellitus and insulin resistance. Am J Perinatol. 2016;33(1):114-21. https://doi.org/10.1055/s-0035-1562928.

30. Takmaz T, Yalvaç ES. The predictive value of weight gain and waist circumference for gestational diabetes mellitus. Turk J Obstet Gynecol. 2019; 16(3):199-204.

31. Han Q, Shao P, Leng J, Zhang C, Li W, Liu G, et al. Interactions between general and central obesity in predicting gestational diabetes mellitus in Chinese pregnant women: a prospective population-based study in Tianjin. China J Diabetes. 2018;10(1):59-67. https://doi.org/10.1111/1753-0407.12558.

32. Thomou T, Mori MA, Dreyfuss JM, Konishi M, Sakaguchi M, Wolfrum C, et al. Adipose-derived circulating miRNAs regulate gene expression in other tissues. Nature. 2017;542(7642):450-5. https://doi.org/10.1038/nature21365.

33. Hubal MJ, Nadler EP, Ferrante SC, Barberio MD, Suh JH, Wang J, et al. Circulating adipocyte-derived exosomal MicroRNAs associated with decreased insulin resistance after gastric bypass. Obesity (Silver Spring). 2017;25(1):102-10. https://doi.org/10.1002/oby.21709.
34. Silambarasan M, Tan JR, Karolina DS, Armugam A, Kaur C, Jeyaseelan K. MicroRNAs in hyperglycemia induced endothelial cell dysfunction. Int J Mol Sci. 2016;17(4):518. https://doi.org/10.3390/ijms17040518.

35. Upadhyay R DH. Differential role of microRNAs miR-221/222 and miR-103/ 107 in type 2 diabetes and effects of metformin. FASEB J. 2014;28(1):851.2.

\section{Publisher's Note}

Springer Nature remains neutral with regard to jurisdictional claims in published maps and institutional affiliations.

\section{Ready to submit your research? Choose BMC and benefit from:}

- fast, convenient online submission

- thorough peer review by experienced researchers in your field

- rapid publication on acceptance

- support for research data, including large and complex data types

- gold Open Access which fosters wider collaboration and increased citations

- maximum visibility for your research: over $100 \mathrm{M}$ website views per year

At BMC, research is always in progress.

Learn more biomedcentral.com/submissions 